\title{
Assessment of a pharmacist-driven point-of-care spirometry clinic within a primary care physicians office
}

\author{
Michael J. CAWLEY, Richard PACITTI, William WARNING.
}

Received (first version): 22-Mar-2011 Accepted: 7-Nov-2011

\begin{abstract}
${ }^{\star}$
Objective: To assess value-added service of a pharmacist-driven point-of-care spirometry clinic to quantify respiratory disease abnormalities within a primary care physicians office

Methods: This retrospective, cohort study was an analysis of physician referred patients who attended our spirometry clinic during 2008-2010 due to pulmonary symptoms or disease. After spirometry testing, data was collected retrospectively to include patient demographics, spirometry results, and pulmonary pharmaceutical interventions. Abnormal spirometry was identified as an obstructive and/or restrictive defect.
\end{abstract}

Results: Sixty-five patients with a primary diagnosis of cough, shortness of breath, or diagnosis of asthma or chronic obstructive pulmonary disease were referred to the spirometry clinic for evaluation. A total of 51 (32 patients with normal spirometry, 19 abnormal spirometry) completed their scheduled appointment. Calculated lung age was lower in normal spirometry (58.1; $\mathrm{SD}=20 \mathrm{yrs})$ than abnormal spirometry (78.2; $S D=7.5$ yrs, $p<0.001)$. Smoking pack years was also lower in normal spirometry (14.4; $\mathrm{SD}=10.7 \mathrm{yrs}$ ) than abnormal spirometry (32.7; $\mathrm{SD}=19.5 \mathrm{yrs}, \mathrm{p}=0.004)$. Resting oxygen saturation of the arterial blood ( $\mathrm{SaO} 2)$ was higher in normal spirometry than abnormal spirometry $(98.1 \%$ vs $96.5 \%, p=0.016)$. Mean change in the forced expiratory volume in one second (FEV1) after administration of bronchodilator was greater in patients with abnormal spirometry compared with normal spirometry $(10.9 \%$ vs $4.1 \%, p<0.001)$. Spirometry testing assisted in addition, discontinuation or altering pulmonary drug regimens in $41 / 51$ patients $(80 \%)$ and the need for further diagnostic testing or physician referral in $14 / 51$ patients $(27.4 \%)$.

Conclusion: Implementation of a pharmacist-driven spirometry clinic is a value-added service that can be integrated with other clinical pharmacy services within the ambulatory care setting. Further studies are needed to determine the role of pharmacists in

\footnotetext{
Michael J. CAWLEY. PharmD, RRT, CPFT. Associate Professor of Clinical Pharmacy. Department of Pharmacy Practice and Pharmacy Administration. Philadelphia College of Pharmacy, University of the Sciences. Philadelphia, PA (United States).

Richard PACITTI. PharmD, MBA. Clinical Manager. Department of Pharmacy, Crozer-Keystone Health System. Upland, PA (United States).

William WARNING. MD. Program Director, Family

Medicine Residency Program, Crozer-Keystone Center for Family Health. Springfield, PA (United States).
}

performing spirometry testing and measuring performance outcomes of the pulmonary patient.

Keywords: Pharmacists. Point-of-Care Systems. Spirometry. United States.

\section{EVALUACIÓN DE UNA CLÍNICA DE ESPIROMETRÍA DIRIGIDA POR UN FARMACÉUTICO EN LA CONSULTA DE UN MÉDICO GENERAL}

\section{RESUMEN}

Objetivo: Evaluar el valor añadido de un servicio dirigido por un farmacéutico de una clínica rápida de espirometría para cuantificar las anomalías respiratorias en una consulta de un médico general. Métodos: Este estudio de cohorte prospectiva fue un análisis de los pacientes referidos por un médico que visitaron nuestra clínica de espirometría durante 2008-2010 debido a síntomas o enfermedad pulmonar. Después de la espirometría, se recogieron retrospectivamente los datos demográficos de los pacientes, los resultados de la espirometría y las intervenciones farmacéuticas. Se identificó una espirometría anormal cuando había una obstrucción o un defecto restrictivo.

Resultados: 65 pacientes con diagnostico primario de tos, dificultad de respiratoria, o diagnóstico de asma o enfermedad pulmonar obstructiva crónica fueron referidos a la clínica de espirometría para evaluación. Un total de 51 pacientes (32 con espirometría normal y 19 con anomalías espirométricas) completó el esquema de citas. La edad pulmonar calculada fue menor en las espirometrías normales $(58,1 ; \mathrm{DE}=20$ años) que en las anormales $(78,2 ; \mathrm{DE}=7,5$ años; $\mathrm{p}<0,001)$. Los años de fumador fueron también menores en las espirometrías normales $(14,4 ; \mathrm{DE}=10,7$ años $)$ que en las anormales $(32,7 ; \mathrm{DE}=19,5$ años; $\mathrm{p}=0,004)$. La saturación en reposo de oxígeno en la sangre arterial $(\mathrm{SaO} 2)$ era superior en las espirometrías normales que en las anormales $(98,1 \%$ vs. $96,5 \%$, $\mathrm{p}=0,016)$. El cabio medio en el volumen espiratorio forzado en un segundo (FEV1) después de la administración de un broncodilatador fue mayor en pacientes con espirometría anormal comparado con las normales $(10,9 \%$ vs. $4,1 \%$; $<<0,001)$. La espirometría ayudó en la adición, discontinuación o alteración de los tratamientos pulmonares en 41/51 pacientes $(80 \%)$ y en la necesidad de pruebas posteriores o derivación al médico en 14/51 pacientes $(24,4 \%)$

Conclusión: La implantación de una clínica espirométrica dirigida por un farmacéutico es un 
servicio de valor añadido que puede integrarse con otros servicios de farmacia clínica en los ambulatorios. Se necesitan más estudios para determinar el papel del farmacéutico realizando espirometrías y midiendo el funcionamiento de los resultados en salud de los pacientes pulmonaes.

Palabras clave: Farmacéuticos. Sistemas de Atención de Punto. Espirometria. Estados Unidos.

\section{INTRODUCTION}

Spirometry is a pulmonary function test that requires a patient to maximally inhale and then maximally exhale into a measuring device. The test is traditionally performed in a specialized pulmonary function laboratory or within a physician's office setting. Spirometry has been used as a screening and diagnostic tool to assist clinician's in the pharmacological management of pulmonary disorders including chronic obstructive pulmonary disease (COPD) and asthma. ${ }^{1,2}$ Also, this test is invaluable to evaluate and monitor patients with respiratory symptoms induced by diseases affecting cardiac and lung function, occupational, environmental and drug exposure, risk of pulmonary complications after surgery and to assist in the evaluation of insurance benefits. ${ }^{3}$ Recently international experts have reassessed the value of spirometry in screening patients without respiratory symptoms. The American College of Physicians (ACP), American College of Chest Physicians (ACCP), American Thoracic Society (ATS) and European Respiratory Society (ERS) clinical practice guidelines now recommend that spirometry should be obtained to diagnose airflow obstruction in patients with respiratory symptoms and should not be used to screen for airflow obstruction in individuals without respiratory symptoms. In addition, the routine use of spirometry in asymptomatic patients in primary care settings may potentially lead to unnecessary testing, increased costs and resource utilization, and unneccesary disease labeling. ${ }^{4}$

Pharmacists are in a unique position to provide spirometry testing based upon their education in pulmonary pharmacotherapeutics, access to the general public to identify patients who may have respiratory symptoms (i.e., cough, shortness of breath), and/or collaboration with physicians to monitor patients with a previous diagnosis of asthma or COPD. Limited studies outside the United States have demonstrated that pharmacists are able to competently perform spirometry testing. ${ }^{5-7}$ However, many questions related to development of these services including financial reimbursement strategies remain unanswered.

The spirometry clinic was designed as a pilot program that can be integrated with other clinical pharmacy services within the ambulatory care setting. The objective of our study was to assess the value-added service of a pharmacist-driven point-of-care spirometry clinic to quantify respiratory disease abnormalities within a primary care physicians office.

\section{Spirometer Clinic Program}

In August 2008, our pharmacy department collaborated with the director of an affiliated family health clinic to initiate a spirometry clinic. The pharmacist was in a unique position to provide this service based upon previous credentials as a Registered Respiratory Therapist (RRT) and Certified Pulmonary Function Technologist (CPFT). The pharmacist identified errors in the quality of the testing that was presently performed by ancillary staff including nurses and medical assistants. Errors in testing included absence of spirometer calibration consistent with the American Thoracic Society (ATS) guidelines for quality spirometry testing. Based upon the needs to optimize the quality of spirometry testing and added value of the pharmacist including educating patients and medical staff in the use of respiratory delivery devices and identifying potential drug/drug or drug/disease interactions the medical director implemented the pharmacist-driven point-of-care spirometry clinic.

The first priority was the purchase of a new spirometer since the previous spirometer was outdated and unreliable. The medical director provided the financial resources to purchase a new spirometer program. The spirometer (CardioPerfect $\AA$ Workstation Software, SpiroPerfect $\AA$ Module, Welch-Allyn $\AA$ Skaneateles Falls, NY, USA) and the flow transducer (Medikro Oy, Kuopio, Finland) were utilized for all testing procedures.

Based upon the number of physician referrals of patients requiring spirometry testing it was decided to initiate the clinic one day per month scheduling five patients. Based upon this model it would require the pharmacist staffing the clinic one day per month for eight hours assuming all patients attended the spirometry clinic. The pharmacist's only responsibility for the family health center was operation of the spirometry clinic and was not responsible for other patients being seen outside the spirometry clinic. Budget support for this program was a moot point since the pharmacist directly responsible for the spirometry clinic was a pharmacy professor at an affiliated pharmacy school and was providing this service as a part of his pharmacy affiliated agreement with the healthsystem.

Patients identified for spirometry testing where referred to the clinic from medical residents within the health clinic or from physicians outside the medical clinic. Patients were contacted by the medical staff via telephone and received instruction prior to visiting the spirometry clinic. Instruction included withholding administering of respiratory medications for 24 hours before spirometry testing to provide a baseline value of pulmonary function. Patients were instructed to administer their rescue inhaler (short-acting beta agonist) if they experienced increased shortness of breath. 


\section{METHODS}

This retrospective, cohort study was an analysis of patients who attended our spirometry clinic during 2008-2010. A clinical pharmacist retrieved electronic data on patients that performed spirometry from Centricity ${ }^{\circledR}$ Electronic Medical Record 9.2 (General Electric Company, United Kingdom). The medical information identified patients screened with spirometry. Inclusion criteria included all patients greater than 8 years of age with a recent history of cough, shortness of breath, pulmonary diagnosis including asthma, COPD or other pulmonary symptoms warranting spirometry testing. Patients were excluded who had contraindications for performing the test including: age less than 8 years of age, systolic blood pressure $>200 \mathrm{mmHg}$ or diastolic blood pressure $>110 \mathrm{mmHg}$, recent myocardial infarction or stroke in the past 3 months, recent history of ophthalmic complications (cataract), chest or abdominal/thorax surgery in past 3 weeks, suffers from angina, has unstable cardiovascular status or recent pulmonary embolism, hemoptysis of unknown origin, pneumothorax, nausea and vomiting, thoracic, abdominal or cerebral aneurysms or taken respiratory medications within 1 hour before the spirometry test. ${ }^{10}$

The spirometer and flow transducer were checked and calibrated at the beginning of each day before patient testing for volume, room temperature and humidity utilizing a $3 \mathrm{~L}$ single stroke calibrated syringe. Both devices were to meet ATS reproducibility for syringe volume which was defined as maintaining a calculated syringe volume reproducibility $<3 \%$ of predicted values. ATS reproducibilty criteria was based upon the 1998 National Health and Nutrition Examination Survey (NHANES III) criteria for patient age, sex, race, height and weight. Calculated lung age was also determined by the software utilizing the calculation from Fletcher and Peto. ${ }^{8}$ Calculated lung age uses linear regression equations to calculate how smoking accelerates age related decline in lung function. The spirometer displayed pre and post bronchodilator flow-volume loop patterns, calculated percent change in all spirometric values and a pulmonary diagnosis of a obstructive or restrictive pattern.

Based upon comprehensive spirometry clinical services to be provided, it was determined that each patient would require approximately 1 hour and 15 minutes receiving all scheduled services. Services included: pulmonary history performed by the physician and pharmacist, pre and post bronchodilator testing, bronchodilator administration of $2.5 \mathrm{mg}$ albuterol sulfate, $0.5 \%$ nebulizer solution (Hi-Tech Pharmacal Co., Inc., Amityville, NY), assessment of the quality of the spirometric results, recommendation of pharmacological intervention and patient education of respiratory delivery device or smoking cessation literature (if applicable) were all performed by the pharmacist. Pharmacological intervention included addition, discontinuation or dose adjustments of current or prescribed pulmonary medications. Each spirometric test (flowvolume loop pre and post) were performed a minimum of three times. Testing continued until the patient achieved the ATS guidelines of a forced vital capacity (FVC) in liters or forced expiratory volume in one second (FEV1) in liters until the value was within $0.2 \mathrm{~L}$ or $200 \mathrm{ml}$ of the next largest value. ${ }^{9} \mathrm{~A}$ maximum of 8 efforts would be attempted. The pharmacist also performed oxygen saturation of the arterial blood (SaO2\%) utilizing a pulse oximeter at rest before and after the spirometry testing. The spirometry results were immediately evaluated by the medical director, pharmacist and medical residents in consultation with the patient to determine an appropriate treatment plan.

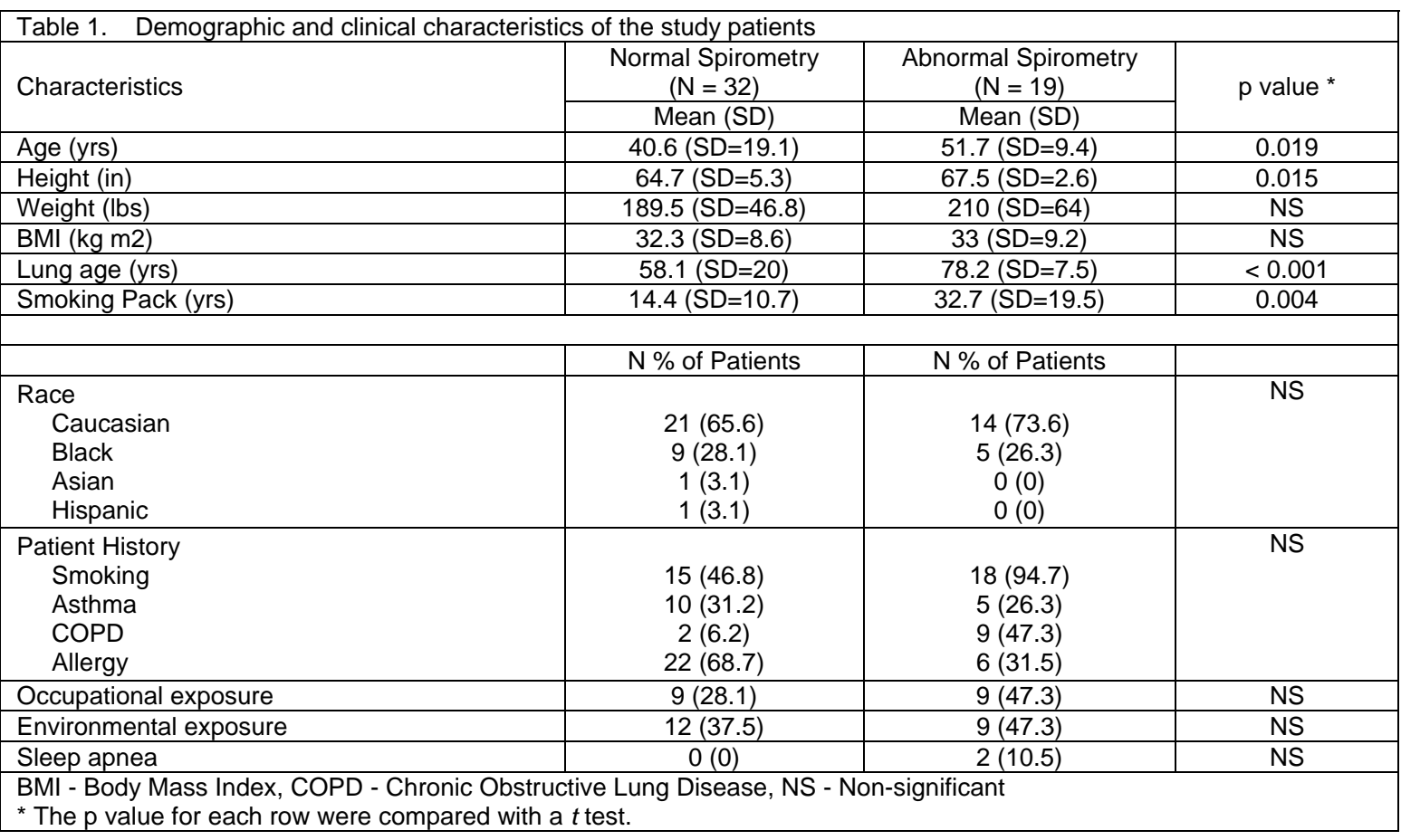




\begin{tabular}{|c|c|c|c|}
\hline \multirow{2}{*}{ Characteristics } & $\begin{array}{c}\text { Normal Spirometry } \\
(\mathrm{N}=32)\end{array}$ & $\begin{array}{l}\text { Abnormal Spirometry } \\
(\mathrm{N}=19)\end{array}$ & \multirow{2}{*}{$p$ value * } \\
\hline & $\begin{array}{l}\text { Pre-bronchodilator } \\
\text { (Mean) }\end{array}$ & $\begin{array}{l}\text { Pre-bronchodilator } \\
\text { Mean }\end{array}$ & \\
\hline FVC (L) & 2.94 & 3.06 & NS \\
\hline $\mathrm{FEV}_{1}(\mathrm{~L})$ & 2.66 & 2.13 & 0.003 \\
\hline $\mathrm{FEV}_{1} / \mathrm{FVC}(\%)$ & 93.5 & 70 & $<0.001$ \\
\hline $\mathrm{FEF}_{25-75 \%}(\mathrm{~L} / \mathrm{sec})$ & 3.72 & 1.47 & $<0.001$ \\
\hline \multirow[t]{2}{*}{ PEFR (L/sec) } & 5.51 & 5.63 & NS \\
\hline & $\begin{array}{l}\text { Post-bronchodilator } \\
\text { (Mean) }\end{array}$ & $\begin{array}{l}\text { Post-bronchodilator } \\
\text { (Mean) }\end{array}$ & $p$ value * \\
\hline FVC (L) & 3.19 & 2.24 & NS \\
\hline $\mathrm{FEV}_{1}(\mathrm{~L})$ & 2.68 & 1.71 & 0.005 \\
\hline $\mathrm{FEV}_{1} / \mathrm{FVC}(\%)$ & 82.5 & 76.5 & $<0.001$ \\
\hline $\mathrm{FEF}_{25-75 \%}(\mathrm{~L} / \mathrm{sec})$ & 3.08 & 1.38 & $<0.001$ \\
\hline PEFR (L/sec) & 4.46 & 4.64 & NS \\
\hline
\end{tabular}

Relevant data included pulmonary diagnosis, prescribed pulmonary medications and results of pulmonary function testing including FVC, FEV1, FEV1/FVC (\%), forced expiratory flow $25 \%-75 \%$ in liters/second (FEF $25-75 \%$ ) and peak expiratory flowrate PEFR in liters/second was collected. Data evaluation included improvements in pulmonary function testing, modifications of pulmonary medications, medication reconciliation or smoking cessation literature and if a specialty physician referral (i.e., pulmonary, cardiologist, allergy/immunologist, etc.) or further diagnostic testing was warranted. A positive post bronchodilator response indicative of reversible airway disease was determined if $>12 \%$ increase in FEV1 and $200 \mathrm{ml}$ increase in FVC or FEV1, or 15 to $25 \%$ increase in FEF $25-75 \%$ was obtained. ${ }^{10}$

The study was approved by the institutional review boards of both the pharmacy faculty member's academic institution and the family health center; the requirement for written informed consent was waived due to the retrospective nature of the study.

Statistical analysis was performed by using SPSS software, version 18.0 for Windows (SPSS Inc., Chicago IL). Descriptive statistics were obtained for all variables. Results were presented as standard deviation, mean and percent. The t test analysis was used to compare continuous variables with a critical $p$ value set at 0.05 .

\section{RESULTS}

A total of 65 patients were scheduled for office spirometry appointments. A total of 51 (32 patients normal spirometry, 19 abnormal spirometry) completed their scheduled appointment and were evaluated for inclusion. (Table 1). The nineteen abnormal spirometry tests were indicative of an obstructive defect ( 9 patients), restrictive defect (7 patients) or combined obstructive/restrictive defect (3 patients). Forty-three percent (22 male) and fiftyseven percent (29 female) completed spirometry testing. Sixty-seven percent (35 patients) were Caucasian, 27\% (14) African-American, 2\% (1) Asian and 2\% (1) Hispanic. Patients with abnormal spirometry demonstrated a greater smoking pack year history and calculated lung age than patients with normal spirometry $(32.7 ; \mathrm{SD}=19.5$ vs 14.4 ; $\mathrm{SD}=10.7 \mathrm{yrs}$ and $78.2 ; \mathrm{SD}=7.5$ vs $58.1 ; \mathrm{SD}=20 \mathrm{yrs}$ respectively). Comparing the difference between pre and post bronchodilator results of patients with normal and abnormal spirometry including FVC, FEV1, FEV1/FVC, FEF $25-75 \%$ and PEFR, significant difference were noted in the FEV1, FEV1/FVC, FEF 25-75\% (Table 2). Also, patients with abnormal spirometry demonstrated a significant improvement in mean percent change in FEV1 after bronchodilator administration compared to normal spirometry $(10.9 \%$ vs $4.0 \%, p<0.001)$ Table 3.

Respiratory medications also required significant adjustment after spirometric testing review (Figure 1 ). Fourteen out of 51 patients $(27.4 \%)$ necessitated discontinuation of respiratory medications and 28/51 (55\%) required additional therapy due to uncontrolled symptoms identified after spirometry testing. Beta agonists were discontinued more than any other therapeutic drug class $8 / 14(57 \%)$. This was based upon spirometric tests indicating a

\begin{tabular}{|c|c|c|c|}
\hline \multirow[t]{2}{*}{ Characteristics } & $\begin{array}{l}\text { Normal Spirometry } \\
(\mathrm{N}=32)\end{array}$ & $\begin{array}{l}\text { Abnormal Spirometry } \\
(\mathrm{N}=19)\end{array}$ & $p$ value * \\
\hline & Mean (\%) & Mean (\%) & \\
\hline Change in $\mathrm{FEV}_{1} \quad(\mathrm{~L})$ & 4.09 & 10.93 & $<0.001$ \\
\hline Change in $\mathrm{FEF}_{25-75}(\mathrm{~L} / \mathrm{sec})$ & 12.51 & 25.43 & NS \\
\hline Positive Bronchodilator Response & $\mathrm{N}$ (\% of Patients) & $\mathrm{N}$ (\% of Patients) & \\
\hline $\begin{array}{l}\mathrm{FEV}_{1} \%>12 \% \text { and } 200 \mathrm{ml} \text { increase in FVC or } \\
\mathrm{FEV}_{1}\end{array}$ & $4(12.5)$ & $6(31.5)$ & NS \\
\hline $\mathrm{FEF}_{25-75 \%}>15 \%$ & 14(43.7) & $9(47.3)$ & NS \\
\hline
\end{tabular}


negative post-bronchodilatory response in conjunction with the patient's medical history inconsistent in obtaining benefit from an inhaled bronchodilator. Leukotriene antagonist prescribing was required much more after results of spirometry testing than any other class for patients accounting for $9 / 28(34.6 \%)$ of prescriptions. The authors attest this to an underlying allergy component not previously identified in the patient's medical history. During the summer months (May - July) of spirometric testing, environmental pollen counts and air quality was compromised.

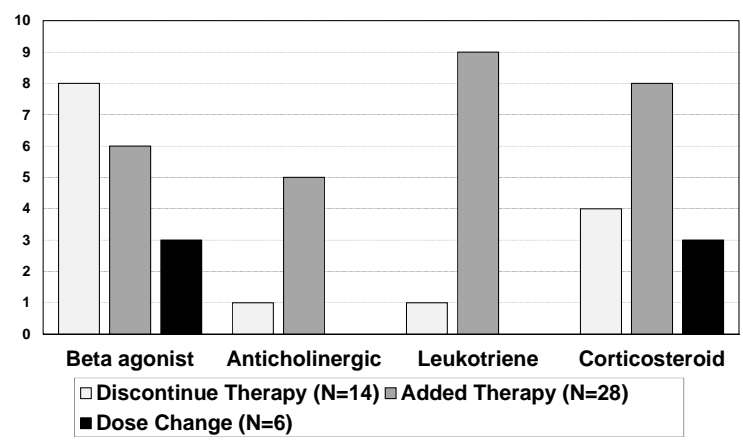

Figure 1. Respiratory Medication Modification. (Corticosteroids include inhaled and oral preparations)

The increase in anticholinergic and corticosteroid prescribing was primarily indicated for the diagnosis of COPD based upon medical history and results of spirometry testing.

Smoking cessation literature was provided to $32 / 51$ $(63 \%)$ of patients. Physician consult referral or further diagnostic testing was required in $27.4 \%$ of patient which included $5 / 51$ (9.8\%) pulmonary, $5 / 51$ $(9.8 \%)$ allergist, immunologist or otolaryngolology and $4 / 51 \quad(7.8 \%)$ cardiologist. The pharmacist achieved ATS guidelines of a FVC or FEV1 within $0.2 \mathrm{~L}$ or $200 \mathrm{ml}$ of the next largest value in $77 / 102$ (75\%) spirometry attempts. One hundred and two attempts included 51 patients performing both pre and post spirometry maneuvers.

Financial reimbursement of spirometry testing was also assessed. The results included the Current Procedural Terminology (CPT) codes of common charges billed in the spirometry clinic. Table 4 provides the Medicare financial reimbursement received for spirometry clinical services. ${ }^{11}$ The charges are listed as billable units assumed all 51 patients to be under Medicare reimbursement. Unfortunately, some patients were under different third party payer coverage. Many insurance or third party payers pay similar to Medicare, thus, Medicare was used as a guide for total reimbursement. The charge listed was billed directly to the patients Medicare or individual insurance provider and is specific for spirometry services provided by the physician. Pharmacists do not have the ability at this time to bill directly for spirometry services.

\section{DISCUSSION}

Pharmacists have demonstrated throughout the medical literature valued services and/or programs including medication therapy management, direct thrombin inhibitor monitoring, immunization administration, smoking cessation and asthma management. ${ }^{12-16}$ In the Ashville Project, long-term interaction with pharmacists led to improved clinical, economic and humanistic outcomes for patients with asthma. ${ }^{17}$ Mehuys et al. also showed improved outcomes for asthmatics that were randomized to a community pharmacist intervention group versus usual pharmacy care. ${ }^{18}$ Weinberger et al. did not find benefit associated with pharmacist care versus aggressive peak flow monitoring, the authors speculated that limited time and lack of incentives to provide the intervention may have compromised the pharmacists' intervention. ${ }^{19}$

\begin{tabular}{|c|c|c|}
\hline $\begin{array}{l}\text { CPT } \\
\text { Code }\end{array}$ & Service & $\begin{array}{c}\text { Medicare } \\
\text { Reimbursement } \\
\text { (US Dollars) }\end{array}$ \\
\hline 94060 & Spirometry (pre and post) & 63.71 \\
\hline 94640 & Nebulizer treatment & 15.01 \\
\hline \multirow[t]{3}{*}{94760} & Pulse oximetry (pre and post) & 7.08 \\
\hline & Reimbursement per patient & 85.80 \\
\hline & Reimbursement for 51 patients & $4,375.80$ \\
\hline \multicolumn{3}{|c|}{$\begin{array}{l}\text { CPT - Current Procedural Terminology, US - United States } \\
\text { Modified from reference }\end{array}$} \\
\hline
\end{tabular}

Spirometry testing outside the hospital setting is well documented and has shown to be invaluable for counseling patients for smoking cessation, predicting postoperative pulmonary complications and influence diagnosis and management for COPD. ${ }^{20-22}$ Although many studies have identified the value of spirometry in clinical practice, to our knowledge this is the only pharmacist-driven spirometry program in the United States. One published descriptive report did discuss the role of pharmacists in recommending spirometry testing in the management of COPD patients. ${ }^{23}$ The report did mention pharmacists were trained in spirometry testing but was not clear if pharmacists actually performed the test in any patients included in the project. Our pharmacist-driven spirometry clinic study is unique since the pharmacist participates in the initial patient pulmonary history interview, performs both pre and post spirometry testing, administers aerosolized bronchodilators, performs pulse oximetry testing, recommends pharmacological intervention, and respiratory drug delivery device education or smoking cessation literature if applicable.

Our study demonstrates that pharmacist can accurately perform spirometry testing and optimize pharmaceutical care for the pulmonary patient. Pharmacists do not routinely perform spirometry testing due to misconceptions that this testing is outside the pharmacist's scope of practice warranting nurses or other medical office personnel to perform this testing in the outpatient setting. Traditionally, respiratory therapists are the primary ancillary medical professional responsible for pulmonary function testing in the hospital environment. Unfortunately, many primary care physicians do not have the luxury to add a respiratory therapist to the medical staff and are 
confined to medical assistance or nursing staff to perform spirometry testing. Also, respiratory therapists are limited in their scope of practice to the pulmonary patient. The pharmacist can provide this value-added service as part of the physician directed team since the pharmacist provides comprehensive pharmaceutical care for patients with other medical conditions including diabetes, hypertension, hyperlipidemia, heart failure, asthma and COPD. This service expands the scope and capabilities of the pharmacist in the outpatient or ambulatory care setting. In our study, therapeutic recommendations provided by the pharmacist to the attending physician was based upon a number of factors including spirometry results, potential drugdrug interactions, patient's medical history, patient prescription insurance coverage and therapeutic guidelines for the treatment of asthma and COPD. ${ }^{1,2}$ Furthermore, the pharmacist educated patients and care-givers on the proper use of prescribed respiratory delivery devices.

Spirometry services can also be implemented within the community setting. Pharmacists can identify patients with respiratory symptoms and implement a collaborative practice with physicians in the surrounding geographical area to monitor patients for airflow obstruction. This service would potentially provide many advantages including optimizing pharmaceutical care of patients with airflow obstruction, convenience of patients not traveling to a pulmonary function laboratory of a hospital to perform spirometry testing and maintain quality documentation of ongoing pharmaceutical care. In addition, since spirometry systems are portable testing can be promoted through health fairs and in the workplace. ${ }^{24}$

Pharmacists can be trained to accurately perform spirometry testing. The ATS has made recommendations that spirometry can be administered by persons who have a high school diploma, with one or more years of college with strong mathematical skills are encouraged, (recommended six months of supervised training in spirometry testing) or (two or more years of college studies in biological sciences and/or mathematics and training that includes two or more years of spirometry testing experience or credentialed as a respiratory technician/therapist or pulmonary function technologist). ${ }^{25}$ If pharmacists would like to become more proficient in performing spirometry testing, either on-the-job training with a respiratory technician/therapist or pulmonary function technologist would be warranted or a pharmacist can take a hands-on workshop or become credentialed. Presently the American College of Chest Physicians and the Association of Nurse Practitioners provide a one day hands-on workshop on proper spirometry techniques. ${ }^{26}$

Unfortunately, since many medical office personnel have limited to no medical training in spirometry many of these testing procedures are performed inaccurately. Inaccuracies of spirometry testing may include not calibrating the spirometer for flow, volume, room temperature and humidity accuracy, improper patient positioning, less than optimum patient coaching, inaccurate documentation of the patient height and weight, less than optimal patient effort, and maintaining flow-volume curve reproducibility based upon recommendation by the ATS. Recent data has determined that only $24 \%$ of general practitioner physicians reported that they were trained to conduct spirometry and $26 \%$ maintained that their training did not adequately equip them to interpret the results. ${ }^{27}$

Pharmacists trained in spirometry testing require financial compensation. Accurate reimbursement for spirometry services requires diagnostic and procedural coding. Proper diagnosis is based upon the International Classification of Diseases, Ninth Edition while procedural codes for billing are based upon the CPT manual. ${ }^{28}$ Spirometry generally requires physician supervision which the physician must be available by telephone or pager during the test. ${ }^{29}$ Also, the location of testing including the physicians office, hospital laboratory, outpatient clinic impacts how the procedure can be billed (CPT code). When the testing is completed in a physician's office (physician owns and maintains the equipment) the spirometry testing is listed under the procedural code CPT 94010, which includes the performance and interpretation of the testing. "Bundling" is another method that payers may use for reimbursement which uses "edits" in their computerized billing processing system. An example includes billing for spirometry (CPT 94010) but if you would perform a pre and post bronchodilator test the CPT code would be $94060 .^{30}$ Medicare traditionally pays the lower code rate but allowable amounts may vary based upon geographic region. Since transcribing proper CPT codes are vital for optimum financial reimbursement, it is best to discuss billing procedures with your in-house reimbursement specialists. Pharmacists must become familiar with procedural codes for billing of supportive services. Other references are available that will help with the procedural billing and is beyond the scope of this article. $^{31}$

\section{CONCLUSIONS}

Implementation of a pharmacist-driven spirometry clinic is a value-added service that can be integrated with other clinical pharmacy services within the ambulatory care setting. Further studies are needed to determine the role of pharmacists in performing spirometry testing and measuring performance outcomes of the pulmonary patient.

\section{CONFLICT OF INTEREST}

There is no conflict of interest with any of the authors. No sources of financial support are identified. 


\section{References}

1. Global Initiative for Chronic Obstructive Lung Disease. Global Strategy for the Diagnosis, Management, and Prevention of Chronic Obstructive Pulmonary Disease. Global Initiative for Chronic Obstructive Lung Disease; 2009. Available from http://www.goldcopd.org/uploads/users/files/GOLDReport07 Changes.pdf (Accessed September 24, 2011).

2. Expert Panel Report 3: Guidelines for the Diagnosis and Management of Asthma 2007. Available from http://www.nhlbi.nih.gov/guidelines/asthma/ (Accessed September 22, 2011).

3. Crapo RO. Pulmonary Function Testing. N Engl J Med. 1994;331(1):25-30

4. Qaseem A, Wilt TJ, Weinberger SE, Hanania NA, Criner G, van der Molen T, Marciniuk DD, Denberg T, Schünemann H, Wedzicha W, MacDonald R, Shekelle P; American College of Physicians; American College of Chest Physicians; American Thoracic Society; European Respiratory Society. Diagnosis and management of stable chronic obstructive pulmonary disease: A clinical practice guideline update from the Am College of Physicians, Am. College of Chest Physicians, Am. Thoracic Society, and Eur. Respiratory Society. Ann Intern Med. 2011;155(3):179-191.

5. Castillo D, Guayta R, Giner J, Burgos, F, Capdevila C, Soriano JB, Barau M, Casan P, FARMAEPOC group. COPD case findings by spirometry in high-risk customers of urban community pharmacies: A pilot study. Respir Med. 2009;103(6):839-45.

6. Celli BR, MacNee W. ATS/ERS Task Force. Standards for the diagnosis and treatment of patients with COPD: a summary of the ATS/ERS position paper. Eur Respir J. 2004;23:932-946.

7. Burton MA, Burton DL, Simpson MD, Gissing PM, Bowman SL. Respiratory function testing: The impact of respiratory scientists on the training and support of primary health care providers. Respirology. 2004;9:260-264.

8. Fletcher C, Peto R. The natural history of chronic airflow obstruction. BMJ. 1977;1(6077):1645-1648.

9. American Thoracic Society. Standardization of spirometry, 1994 update. Am J Respir Crit Care Med. 1995;152:11071136.

10. Barreiro T, Perillo I. An approach to interpreting spirometry. Am Fam Physician. 2004;69:1107-1114.

11. Cawley MJ, Pacitti R, Keenan D. Reaping the rewards of a pharmacist-run spirometry clinic. Pharmacy Purchasing and Product. 2010;7(12):24-26.

12. Johannigmn MJ, Leifheit M, Bellman N, Pierce T, Marriot A, Bishop C. Medication therapy management and condition care services in a community-based employer setting. Am J Health Syst Pharm. 2010;16:1362-1367.

13. Cooper T, Taber D, Mazur J. Implementation of a collaborative drug therapy management service for inpatients receiving direct thrombin inhibitors. Am J Health Syst Pharm. 2009;14:1297-1303.

14. Wong MD, Manley RT, Stettin G, Chen W, Salmun LM. Intervention to reduce unnecessary dispensing of short-acting \{beta\}- agonists in patients with asthma. Ann Pharmacother. 2010;4:623-629.

15. Bounthavong M, Christopher ML, Mendes MA, Foster EB, Johns ST, Lim L, Rubin LM, Patel JJ, Stewart AG. Measuring patient satisfaction in the pharmacy specialty immunization clinic: a pharmacist-run Immunization Clinic at the Veterans Affairs San Diego Healthcare System. Int J Pharm Pract. 2010;2:100-107.

16. Baggarly SA, Jenkins TL, Biglane GC, Smith GW, Smith CM, Blaylock BL. Implementing a Referral to Telephone Tobacco Cessation Services in Louisiana Community Pharmacies: A Pilot Study. Ann Pharmacother. 2010;44(9):13951402.

17. Bunting BA, Cranor CW. The Ashville project: long-term clinical, humanistic, and economic outcomes of a communitybased medication therapy management program for asthma. J Am Pharm Assoc. 2006;46:133-147.

18. Mehuys E, Van Bortel L, De Bolle L, Van Tongelen I, Annemans L, Remon JP, Brusselle G. Effectiveness of pharmacist intervention for asthma control improvement. Eur Respir J. 2008;31(4):790-799.

19. Weinberger M, Murray MD, Marrero DG, Brewer N, Lykens M, Harris LE, Seshadri R, Caffrey H, Roesner JF, Smith F, Newell AJ, Collins JC, McDonald CJ, Tierney WM. Effectiveness of pharmacist care for patients with reactive airways disease. JAMA. 2002;288:1594-1602.

20. Deane K, Stevermer JJ. Help smokers quit: Tell them their "lung age". J Family Pract. 2008;57:584-586.

21. Jacka M, Cheng A, McAlister F. Do history, physical, and spirometry predict pulmonary complications? Canadian J Anesth. 2002;49:A96.

22. Dales RE, Vandemheen KL, Clinch J, Aaron SD. Spirometry in the primary care setting. Influence on clinical diagnosis and management of airflow obstruction. Chest. 2005;128:2443-2447.

23. Mann RP, Zaiken K. Management of chronic obstructive pulmonary disease by pharmacists in an internal medicine department. Am J Health-Syst Pharm. 2009;66:890-893.

24. Bluml BM. White paper on expanding role of pharmacists in chronic obstructive pulmonary disease. J Am Pharm Assoc. 2011;51:203-211.

25. American Association for Respiratory Care clinical practice guideline: Spirometry. Respir Care. 1996;41:629-636.

26. The American College of Chest Physicians. Available from http://www.chestnet.org/accp/events/copd-what-really-works. (Accessed September 26, 2011).

27. Jarrold I, Morrell J, Huntly K, Eiser N. An on-line survey of clinicians on distinguishing between COPD and asthma. Presented in abstract format. European Respiratory Society 19th Annual Congress. Abstract 4561.

28. Beebe M, Dalton JA, Espronceda M, Evans D, Glenn R. CPT 2007 professional edition. Chicago, IL: American Medical Association, 2007;400.

29. Diamond E. Pulmonary function and exercise testing. In: Manaker S, ed. Appropriate coding for critical care services and pulmonary medicine 2007. New Berlin, WI: Northbrook, 2007:161-175.

30. Lange NE, Mulholland M, Kreider ME. Spirometry. Chest. 2009;136:608-614.

31. Maclntyre NR, Foss C. Pulmonary function testing: Coding and Billing Issues. Respir Care. 2003;48:786-790. 